\title{
Editorial
}

\section{Para una ética de la profesión docente}

Poco antes de las pasadas elecciones, una alumna de la UCA le pidió a un catedrático que la aconsejara sobre su elección politica, lo cual dio paso a algunas reflexiones históricas, políticas y morales. Pero, claro, como el ambiente estaba caldeado y no era indiferente a la política del país, le fue imposible presentar las cosas de manera "neutral"; asi que, constantemente, tenía que ser enfático sobre este becho y sobre la prudencia que ella deberia tener al respecto. Aún asi, todas sus precauciones no lograron quitarle de la cabeza la idea de que, a lo mejor, no babia becho lo que debia.

Esta anécdota nos permite notar algunas cosas sobre la profesión docente. Primero, que su carácter ético no viene determinado por unos "temas" éticos que podrían ser tratados y que, en efecto, lo son. Segundo, que tal carácter ético tampoco es algo que obedece meramente a unos conocimientos especificos que el docente debe dominar o a una órbita pedagógica en la que estaría especializado. Tercero, que las interpelaciones morales legitimas nos acometen tanto dentro como fuera del aula. 
Sobre lo primero, es evidente que la pregunta sobre las elecciones políticas no es del mismo tono que si se bubiera consultado sobre algún problema de moral sexual, o sobre si es correcta o no la eutanasia. Tampoco se trata de que la elección de un determinado partido o candidato sea algo ajeno a la moral. El asunto es que, quienes ejercen la docencia, no sólo tienen que esforzarse en responder seguin la teoría o teorias adecuadas, sino que fuera cual fuera el énfasis atinente al valor de sus respuestas, en tal respuesta ya se comprometen moralmente, pues deben responder a la pregunta desde un especial involucramiento. Ese "nexo" o "vinculo" que se babría establecido no depende de la temática contenida en la pregunta, sino del contexto en el que la "alumna" pregunta al "maestro". Por lo tanto, no se esperaría cualquier tipo de respuesta, sino que, por lo menos, debería contener verdad y una sincera pretensión de bondad. Puede que la respuesta fuera en última instancia "buena" o "mala", pero lo que no puede escamotearse es que lo que se esperaba de ella era esa pretensión de bondad, fundada en la verdad. Los maestros no dejan nunca de ser interpelados moralmente por sus alumnos.

En cuanto a lo segundo, también queda claro que la pregunta involucra a la persona consultada, en tanto ella misma se bace o podría bacerse tal cuestionamiento. De tal modo, no es sólo la persona quien preguntó primero la que sería transformada por la respuesta, sino que ésta - la respuesta - compete intimamente a quien escucha la pregunta y responde. $Y$ esa "proximidad" significa que se vuelve pregunta para ella y le interpela, ya no desde el vinculo arriba señalado, sino desde si misma y para sí misma. Entonces, la verdad y la bondad son también para "mí" y no sólo dentro de la legitima pregunta que plantea el alumno en cuestión. Los maestros no dejan nunca de ser interpelados personalmente por los problemas morales de sus alumnos.

$Y$, sobre el tercer asunto, pues, ¿̇qué decir que no sea ya repetitivo? Profesión ingrata ésta, ya que por si fuera poco que los maestros tengan que llevarse los exámenes y trabajos a casa, resulta que el asunto está lejos de acabar alli. A "casa", y no sólo allí, se llevan 
legitimas cuestiones que preocupan a los estudiantes y no sólo porque podrian ser abordados en la calle o por correo electrónico para preguntar sobre cualquier cosa, sino porque la docencia que se precie se construye en el día a día y de cara a las realidades que afectan con mayor fuerza a quienes son parte esencial del mundo del docente. Profesión estimulante ésta, que exige renovar constantemente un compromiso con la verdad y la buisqueda nunca fácil del bien, en un mundo que frecuentemente reniega de su condición de "cosmos" para asumir la de "caos". Pero, una vez más, alli no termina la cosa, ya que la casa, la calle y la plaza deberán ser llevadas por el docente al aula, so pena de convertirse éste en mero repetidor de ideas tal vez brillantes pero vacias. Ética y mundo, no podría ser de otro modo. Los maestros no dejan nunca de ser interpelados mundanalmente por los problemas morales de sus alumnos.

Ignacio Ellacuría nunca se cansó de repetir que la cátedra fundamental en la universidad debia ser "la realidad nacional". $Y$, claro, no se trata de convertir esto en receta, sobre todo si lo que tenemos en mente es la docencia en general y no sólo la universitaria. Abora bien, la docencia, desde la primaria basta la superior, debe estar penetrada por esta realidad en toda su complejidad $y$ con todas sus contradicciones. Esto si quiere ser un instrumento que ponga poder en manos de la persona de la calle y no sólo un mecanismo de dominio por parte de la élite gobernante.

Pero, ¿podriamos hacer esto si la educación y, sobre todo, la educación superior termina estando dirigida para una élite? En efecto, un inicial y fundamental problema para la educación vendria a ser el de la justicia en nuestras sociedades, la justicia educativa, en cuanto al acceso a ella y a que ésta garantice verdaderas posibilidades de una vida digna. Por supuesto, no se trata de aplazar las responsabilidades éticas en el ejercicio de la docencia basta que tales metas sean alcanzadas, pero si de convertir tal aspiración en el norte que oriente la labor docente y en el núcleo de su talante moral. 
Augusto Hortal señala que, cuando se trata de la ética del docente, debemos tomar en cuenta tres principios, sobre los cuales podemos señalar algunas consideraciones:

- Beneficencia: El docente no sólo busca bacer el bien, como si se tratase nada más de construir un mueble (que sirva para sentarse) o una medicina (que sirva para curarse). Se trata, sobre todo, de transmitir unos valores y una opción de vida. Claro que se proporcionaría al educando muchas cosas útiles, pero se trata de algo más: transmitir un modo de ver el mundo y la vida, una opción por bacer de la propia vida algo bueno. Es optar por la felicidad y por poner todo el empeño racional en la consecución de la misma.

- Autonomia: Hay que encontrar el adecuado equilibrio que permita mantener ese compromiso con el mejoramiento de las personas, pero sin que eso derive en pasar por encima de su libertad. Una educación buena está comprometida con el respeto de la autonomía de los demás. En el caso de la universidad, qué duda cabe. Pero, si se trata de niños o adolescentes, es fácil divagar entre un permisivismo absurdo e inútil y la apelación a su "minoría de edad", que termina convirtiéndose en bábil subterfugio para aplazar indefinidamente la construcción de patrones democráticos $y$ participativos, tan necesarios para la configuración del carácter del ciudadano que necesitamos.

-Justicia: La educación que se hace de espaldas a la sociedad y a sus contradicciones no es sólida, y pervierte fatalmente las dos dimensiones mencionadas de la beneficencia y la autonomía. No se es feliz ni se vive en libertad perpetuando, ignorando o padeciendo estructuras sociales injustas o'instituciones politicas ilegitimas (por inmorales). A las naturales aspiraciones de vivir bien $y$ libremente bay que anadir las exigencias que surgen de una mirada amplia y de una razón con pretensión de universalización, aunadas al abrazo de acogida que se dispone a recibir a los compañeros de viaje y a los otros. 
Pero con respecto a la docencia universitaria, Augusto Hortal hace una anotación. No es la labor universitaria algo unicamente dirigido bacia y por la docencia, sino que ésta es el resultado de la consagración a una actividad muchas veces olvidada: la investigación. Las universidades encuentran su razón de ser en una investigación dinámica y comprometida con la buisqueda de la verdad dentro de un mundo cambiante y complejo; $y$ esta investigación baya su necesaria complementariedad en la docencia universitaria, que no debe ser vista, por lo tanto, como mera transmisión de datos sin orientación alguna, sino como una "escuela" que prepara para el indefectible talante cientifico que debe caracterizar al profesional actual. Se trata, por una parte, de un aporte a la sociedad que es un fin en si mismo, al poner en manos de ésta unos resultados que proyectan una mirada más profunda sobre la realidad. Pero, a la vez, la investigación deviene en la creación de una comunidad de investigadores $y$ de quienes se preparan en tales menesteres, aunque no todos se dedicarán a la investigación como profesión.

Esto nos permite volver al pensamiento de Ellacuria, señalando dos cosas. Por un lado, la coincidencia con esta perspectiva, la de las dos funciones de la labor universitaria. $Y$, en segundo lugar, la necesidad de una tercera, la proyección social, la cual se podría derivar también de esa referencia a la justicia que bace el mismo Hortal. El Padre Ellacuría daba a esta función universitaria (la proyección social) un papel predominante, al punto que las otras dos (docencia e investigación) no serían más que sus subordinadas. Eso si, es obvio que tales afirmaciones no se pueden comprender sin una referencia específica a la realidad salvadoreña de las últimas décadas del siglo pasado, por lo que el esquema rector de la actividad académica de la universidad deberá actualizarse constantemente.

Algo asi vemos en las palabras del actual rector de la UCA, el Padre José María Tojeira, pronunciadas en el pasado mes de septiembre: 
"Poner racionalidad en la realidad nacional es una tarea ética y, a través de la proyección social, las universidades se comprometen con dicha tarea, al tiempo que forman en valores a sus alumnos. Racionalidad que es también crítica de lo existente y propuesta de lo nuevo, y que con frecuencia se visualiza en las actividades de proyección social. Si la ética es rentable, como con frecuencia afirman los gurús de la economía, las universidades, que no son exactamente rentables, deberían estar mucho más apoyadas".

Tales menciones a la ética y a la realidad nacional y a la proyección social son profundamente interesantes. Nos permiten establecer un bilo conductor que refleje una estructura académica $y$ una forma especifica de entender la docencia universitaria. Pero no sólo eso, sino que nos permite pensan en dos retos que enfrentan no sólo la educación universitaria sino la totalidad de la actividad docente.

El primero de ellos es el que se trasluce en las palabras finales: la educación en general, y no sólo la universitaria, debería estar más apoyada. Es curioso que a veces la referencia a la necesidad de educar para el desarrollo y la responsabilidad sea utilizada para eximir de responsabilidades al Estado. Y no sólo el Estado es el que se beneficia de esto, ya que al "liberalizarse" la educación, en el sentido mercantil, las instituciones privadas que se dedican a la docencia ya no tienen que preocuparse de si lo que bacen es suficiente para sus "clientes". Lamentablemente, es frecuente ver cómo la educación para la responsabilidad se convierte en una "liberación de responsabilidades sociales", mientras sólo quedan las meras obligaciones corporativas.

Pero no es que el mal esté en "lo corporativo", sino que de lo que se trata, más bien, es de un "choque de racionalidades". Esto nos permite hablar del segundo reto, el que presenta una racionalidad instrumental cada vez más presente en todos los ámbitos de nuestras vidas. $Y$, de nuevo, no es que esta racionalidad, en sí misma, sea necesariamente perjudicial. Al contrario, sin ella no 
podriamos desarrollar tareas fundamentales en el día a día, y no sólo las que tienen un cariz mercantil. Como bien lo señala Franz Hinkelammert, la ciencia misma y la tecnología son, en buena medida, la puesta en práctica de la lógica de unos medios que se disponen para alcanzar determinados fines, cuya necesidad no se pone en duda. El verdadero problema es el de que tal "lógica" se imponga incluso en las situaciones en las que no debería hacerlo.

Ellacuría, en "El concepto filosófico de tecnología apropiada", explicó con bastante claridad cuáles eran sus puntos de vista al respecto, al señalar que una tecnología que se impone por encima del bien común de la sociedad y de las decisiones de sus miembros es una tecnología que abona muy poco a la justicia y al desarrollo. Asimismo, una tecnología sería apropiada no sólo en tanto parte de la realidad concreta de los interesados en su aplicación, o de los afectados por ella, sino que, sobre todo, lo es en tanto se orienta mediante una finalidad que no se reduce al mero cálculo instrumental, sino que se basa en una elección sobre el mejor modo de sociedad y de ser bumano que podriamos alcanzar. En otras palabras, la técnica debe estar "penetrada" por la ética.

De lo que se trata es de pasar de la instrucción de comandos, segun el estilo de la mera racionalidad instrumental, al cultivo de una racionalidad comunicativa $y$ de una razonabilidad ética. Podemos ilustrar esto con otra anécdota: En El Salvador, el inicio de cada nuevo semestre de clases hace pensar (y temer) que se está recibiendo personas que tienen dificultades para "leer" en los acontecimientos, con todo lo que eso supone. Prefieren leer los "comandos" en la red informática, que realizan de inmediato lo que se desea y no generan más molestia que un recuadro avisando que bay algun tipo de "falla". Pero, claro, tal falla nunca exige deliberaciones de indole moral. Es evidente que es mucho más difícil leer en los propios deseos, aspiraciones, principios y deberes. Por ello hay razones para sospechar del ascenso del pensamiento hegemónico neoliberal, el cual no genera más que miedo a pensar con la propia cabeza, tal como lo vemos en quienes prefieren las salidas fáciles: recetas, manuales del usuario o las respuestas al final del 
libro de texto. Por ello podemos sostener que, en el caso de los docentes, justo para enfrentar a este "sujeto" es que nos preparan las discusiones sobre ética. Y esto es igual si lo bacemos en la universidad, en la secundaria o en la primaria.

Retomando las palabras del Padre Tojeira, una ética docente deberá estar orientada a formar jóvenes buscadores de si mismos, libres para elegir con responsabilidad, a la vez que son capaces de ver el entramado de relaciones y vinculaciones que configuran concreta e históricamente esas responsabilidades. Jóvenes conscientes de los valores frente a los que deben optar, orientados bacia los procedimientos democráticos y dispuestos a dirigir sus vidas según un empeño consecuente y sostenido. Si se trata del equilibrio entre una búsqueda personal de la felicidad y las exigencias que impone la vida colectiva, la docencia realizada con consciencia moral es la que cultiva la prudencia, la sabiduría práctica, según señala Paul Ricoeur, $y$ que se ejercita a favor de la construcción de una convicción y no meramente en la observancia.

Algo más, el papel del docente es el de ser facilitador de la esperanza y de la utopía, "crítica de lo existente y propuesta de lo nuevo". Eso significa, básicamente, dos cuestiones, las cuales se encuentran entrelazadas. Por un lado, educar para una población joven que, según Ulrich Beck, se está constituyendo según una "ética de la realización y la responsabilidad personales". Esto significa que cada vez serán más las preguntas que se harán y más difíilles, porque a lo largo y ancho del planeta bay un interés en la ética que no es sólo teórico, sino que brota de la aspiración misma de realización que cada uno ve para si mismo.

Pero tal búsqueda "personal" no debe ser interpretada como una renuncia a lo político. El que baya una disminución en el interés por participar en política formal, mediante los partidos tradicionales y otras instituciones como iglesias y sindicatos, no significa que baya un menor interés en la politica, entendida como una participación activa en proyectos $e$ instituciones no jerárquicas o no tradicionales. El mismo Beck señala que lo que se encuentra en juego 
es una manera diferente de entender la ciudadania, más abierta, pluralista y participativa, pero ciudadania en fin.

$Y$ en función de esto último, las universidades y la docencia universitaria tienen una contribución especial que hacer. En la misma ponencia del Padre Tojeira leemos:

"La universidad abre posibilidades a la ética ciudadana. No sólo porque muchas sirven asignaturas de ética profesional, sino también porque tienen unos rasgos de racionalidad de los que con frecuencia carecen otras instituciones. Ninguna institución salvadoreña es evaluada sistemáticamente como la universidad, a través de un sistema de pares independientes y no manipulables políticamente o de una comisión de acreditación de muy alto nivel. Al contrario de otras instituciones, muchas de ellas públicas, que prefieren la impunidad a la evaluación externa."

No sólo se contribuye a la "ética ciudadana" bablando sobre ella o proponiendo cursos en las diversas carreras que se sirven, sino que el conjunto de la actividad universitaria realiza su mejor contribución moral al someterse a la evaluación que la sociedad bará sobre su labor. Para ello, como dice Adela Cortina, bay que romper con la lógica del "mínimo legal" del ethos burocrático: no más evasivas al escrutinio y a la protesta legitima, que reclaman una verdadera responsabilidad y no sólo la ciega observancia de unas reglas esclerotizadas y esclerotizantes. Esto implica, siguiendo a la autora, apostar por un nuevo ethos, el ethos profesional, que sustituye aquella lógica del burócrata, tan susceptible de trocarse en perversa. Ethos profesional es, a su vez, apostar por una lógica de la "excelencia", la de quien no sólo observa las reglas mínimas sino que pretende dar lo mejor de sí, y contribuir responsablemente al bien propio y de los demás.

La apuesta por la excelencia del profesional es la apuesta por una docencia ética y no sólo por "incluir la ética en la docencia". Esto debe entenderse como un esfuerzo sostenido en aras de la construcción de esferas de intercambio racional, abiertas, partici- 
pativas, $y$ siempre sujetas a la evaluación responsable y necesaria. Libertad $y$ creatividad, frente a las viejas $y$ nuevas burocracias estatales $y$, sobre todo, frente a las burocracias no tan evidentes de nuestros tiempos: las burocracias privadas, las cuales, como señala Franz Hinkelammert en escritos recientes, están constituidas por las corporaciones multinacionales, "empresas de producción mundial", que no son marginales ni de cerca, sino que se han convertido, en los tiempos que corren, en los sujetos económicos que pretenden configurar no sólo el mercado y sus reglas sino el conjunto de relaciones, valores $y$ vinculos que conforman nuestras sociedades, $y$ esto mundialmente.

En suma, bay que considerar la necesidad de situar nuestras reflexiones sobre la ética docente a partir de un compromiso pleno con la construcción de un ideal de ciudadania, en las personas y en las instituciones, $y$ dentro del marco más amplio de la globalización $y$ de la inserción problemática de nuestros países centroamericanos en ella.

\section{REFERENCIAS BIBLIOGRÁFICAS}

Beck, U., Un nuevo mundo feliz, Barcelona, Ediciones Paidós, 2000

Cortina, A., "Presentación", en Diez palabras clave en ética de las profesiones, Navarra, Editorial Verbo Divino, 2000

Ellacuría, I., "El concepto filosófico de tecnología apropiada", en Escritos filosóficos, tercer volumen, San Salvador, UCA Editores, 2001

Ellacuría, I., Escritos universitarios, San Salvador, UCA Editores, 1999

Hinkelammert, F., El grito del sujeto, San José, Editorial DEI, 1998

Hinkelammert, F., "El socavamiento de los derechos humanos en la globalización actual: La crisis de poder de las burocracias privadas", Realidad 87 (2002) 315-330 
Hortal, A., "Docencia", en Diez palabras clave en ética de las profesiones, Navarra, Editorial Verbo Divino, 2000

Ricoeur, P., "Ética y moral", en Gómez, C. (ed.), Doce textos fundamentales de la Ética del siglo XX, Madrid, Alianza Editorial, 2002

Tojeira, J.M., "Contribución de la Educación Superior al desarrollo de El Salvador", ObjetivoUCA 41 (2004) 9 